\title{
EDITORIAL
}

\section{Faltas éticas en autoría de las publicaciones}

Autor es aquel académico que ha contribuido de forma significativa al desarrollo del producto final llamado publicación científica y cumple tres criterios; (a) concepción del estudio, recolección de datos o interpretación de los resultados; (b) redacción del artículo o revisión crítica del mismo; y, (c) aprobación de la versión final que será enviada a publicación. Un autor que aparece en una publicación y no cumple con estos criterios implica que se ha cometido falta ética en autoría denominada PUBLICACIÓN DE REGALO. Considero, intuyo y estoy casi seguro, regalar publicaciones es la falta ética más frecuente que se está cometiendo en el Perú motivada por las presiones de publicar o por mejorar las condiciones económicas del investigador. La nueva Ley Universitaria, Ley 30220, el licenciamiento y el modelo de calidad de acreditación de carreras, están promoviendo obligaciones a cumplir y con ello, mayor presupuesto o incentivos económicos, como premio al cumplimiento de ciertas exigencias en publicaciones.

Otra falta ética en autoría de las publicaciones está relacionada con el ORDEN DE AUTORES. El criterio en este caso es dar el crédito de aparecer como primer autor a la persona que más tiempo y esfuerzo dedicó al desarrollo de la investigación y publicación, los demás autores se ordenan en función de su participación. Normalmente el autor responsable por la publicación, llamado "autor correspondiente", va al final, aunque en función de su participación podría luego de los autores principales. Lo más importante para el líder del grupo de investigación debe ser aparecer como "autor correspondiente" y no como primer autor. La sociedad científica considera al "AUTOR CORRESPONDIENTE" como la persona más importante de la publicación.

Finalmente, la detección de faltas éticas en autoría podría acarrear dos penalidades de parte de la revista que recibió o publicó el trabajo: (a) retiro de la publicación, cuando la falta ética se detecta antes de la publicación; y (b) retractación de la publicación, cuando la falta ética se detecta después de la publicación. Obviamente, lo más grave es el segundo caso, ya que el artículo con falta ética no se retira del sitio donde se publicó, pero que se le coloca un sello de RETRACTACIÓN y explicando el motivo que generó esta situación. Así, es importante culturizar a los científicos peruanos para evitar las faltas éticas en autoría, ya que a la larga podrían generar desprestigio y muerte académica.

Ph D. Raúl Siche Jara 